\title{
Author Correction: Expanding astronomy research in Malaysia
}

Zamri Zainal Abidin (D), Mhd Fairos Asillam and Jun Yi Koay (1D

Correction to: Nature Astronomy https://doi.org/10.1038/s41550-020-01230-x, published online 14 October 2020.

In the version of this Comment originally published, in the caption of Fig. 1 the name of the Langkawi National Observatory was translated incorrectly from English to Malaysian as 'Balai Cerap Kebangsaan Langkawi' and should instead have read 'Observatori Negara Langkawi. This has now been corrected.

Published online: 21 October 2020

https://doi.org/10.1038/s41550-020-01256-1

๑) Springer Nature Limited 2020 